\title{
Immunoglobulin levels in maternal blood, cord blood and breast milk of Nigerian pregnant women using hydroquinone and non-hydroquinone containing skin lightening creams
}

\section{Agatha Obiageli Nwosu, Arinola Olatunbosun Ganiyu}

\author{
Department of Chemical Pathology, College of Medicine University of Ibadan, Ibadan, Nigeria
}

Corresponding author: Prof. Arinola Olatunbosun Ganiyu, E-mail: drarinolaog64@yahoo.com

\begin{abstract}
Background: Skin lightening is practiced by pregnant women whose skin gets darker due to increased skin pigmentation arising from pregnancy associated hormonal changes but report on the levels of immunoglobulin (Ig) classes in pregnant users of skin lightening creams or their babies was not encountered. This study was carried out to assess immunoglobulin levels in maternal blood, cord blood and breast milk of Nigerian pregnant women using hydroquinone and non hydroquinone containing skin lightening creams. Method: Sixty participants were recruited for this study. Thirty of them were daily users of skin lightening creams for six to seven years, while the remaining thirty participants never used skin lightening creams served as controls. Skin lightening creams were classified as hydroquinone containing or hydroquinone lacking based on manufacturer instructions. Levels of mercury $(\mathrm{Hg})$ and $\operatorname{Ig}$ classes (IgG, A and $\mathrm{M}$ ) were measured in maternal sera, cord sera and breast milk plasma using Atomic Absorption Spectrophotometry (AAS) and enzyme-linked immunosorbent assay(ELISA) respectively. The data were presented as mean \pm SD and analyzed using Student t-test. Results: The levels of $\mathrm{Hg}$ in maternal sera $(0.37 \pm 0.05 \mu \mathrm{g} / \mathrm{dl})$ of users of hydroquinone containing skin lightening creams was statically significantly higher when compared with the levels of $\mathrm{Hg}(0.32 \pm 0.05 \mu \mathrm{g} / \mathrm{dl})$ in users of non-hydroquinone containing creams $(\mathrm{p}<0.05)$. Maternal serum IgG, cord IgG and breast milk IgG of the pregnant women using skin lightening creams were significantly higher when compared with the controls. Also, the mean maternal IgM, cord IgM and breast milk IgM of the pregnant women using skin lightening creams were significantly higher when compared with the controls ( $\mathrm{p}<0.05$ ). Statically significant differences were observed when the mean levels of maternal $\operatorname{IgA}(246.08 \pm 90.30 \mathrm{mg} / \mathrm{dl})$, cord IgA $(256.21 \pm 111.91 \mathrm{mg} / \mathrm{dl})$ and breast milk IgA $(244.07 \pm 104.08 \mathrm{mg} / \mathrm{dl})$ in users of hydroquinone containing skin lightening creams were compared with the levels of maternal IgA $(253.39 \pm 78.02 \mathrm{mg} / \mathrm{dl})$, cord $\operatorname{IgA}(264.74 \pm 86.16 \mathrm{mg} / \mathrm{dl})$, and breast milk $\operatorname{IgA}(260.54 \pm 78.98 \mathrm{mg} / \mathrm{dl})$ in users of non - hydroquinone containing skin lightening creams ( $\mathrm{p}>0.05$ ). Conclusion: Raised $\operatorname{IgG}$ and $\operatorname{IgM}$ in mothers and babies of skin lightening creams users could be a result of polyclonal B lymphocyte activation which may lead to autoimmune disease later in life. Also, Hg but not hydroquinone had negative effect on babies' immunoglobulin levels. Recommendation: There is need for public awareness programs to enlighten the populace about the danger involved in the use of skin lightening creams particularly among pregnant women.
\end{abstract}

Key words: Immunoglobulins; Pregnancy; Skin lightening creams

\section{INTRODUCTION}

Skin lightening cream, refers to any substance or mixture used for the purpose of lightening the skin color. It lightens the skin by inhibiting the production of tyrosinase, an enzyme used in synthesis of melanin, the dark skin pigment. This action does not bleach the existing skin pigment but stops the formation of new dark pigment. A significant proportion of individuals misuse these products thereby over lightening their skins.

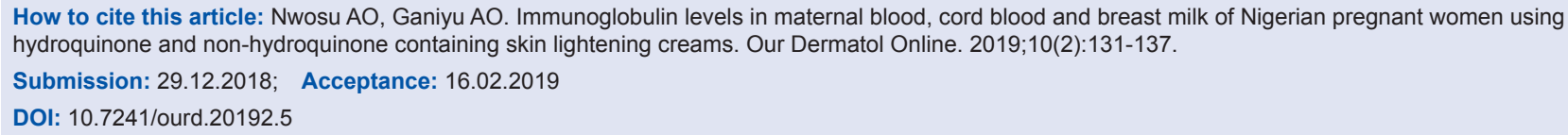


Though this practice is seen at all ages in both sexes, some studies have reported a much higher prevalence among pregnant women whose skin gets darker during pregnancy due to increased skin pigmentation arising from pregnancy associated hormonal changes [1]. Apart from pregnancy, other reasons for skin lightening is either for fame, cosmetic purposes or also due to the presumed superiority and desirability of fair skin [2]. Yet the effect of skin lightening creams on the health of pregnant women is given little attention.

The active components of these skin lightening products include hydroquinone, mercury and steroid [1] which with constant use may crossthe placenta and cause harm to the fetus or pass to the breast milk and cause harm to the infant. Misuse of skin lightening products is becoming rampant in Africa, and especially in Nigeria $[1,3,4]$.Disruption of primary innate function of the epidermis in the process of skin lightening through the chemical agents in these skin lightening creams have been reported and may possibly lead to susceptibility of the users to localized or systemic infections [5]. Hence the need to assess humoral immunity in pregnant women using skin lightening creams.

Topical application of mercury products lead to absorption and eventual mercury poisoning which is manifested by a range of symptoms including psychiatric, neurological and kidney problems [6]. Mercury has been reported to cause immunologically mediated diseases such as glomerulonephritis, acrodynia, contact allergy and fetal abnormalities [7]. Pregnant women using skin lightening creams containing steroid are more likely to have smaller placenta and give birth to low - birth -weight babies though baby's stomach was shown not to absorb steroids [8].

Since skin lightening creams has been shown to cause immunologically mediated diseases skin inflammation and suppression of innate immunity. Moreover, pregnancy is a known state of immunomodulation. Thus, there in need to assess the level of immunoglobulin (Ig) classes and $\mathrm{Hg}$ in maternal blood, cord blood and breast milk of Nigerian women using skin lightening creams.

\section{SUBJECTS AND METHODS}

\section{Subjects}

A total of sixty (60) pregnant Nigeria women participated in this study. Thirty (30) of them were daily users of skin lightening creams for between 6-7 years, while the remaining thirty subjects were pregnant nonusers of skin lightening creams served as controls. The subjects were recruited from two maternity centers in Ibadan, Nigeria. Those on special medication, history of recent blood transfusion, those with various infections, those with complicated pregnancy, those on special diet and those with pre- term delivery were excluded from the study. The subjects aged between 26 years -32 years.

\section{Classification of Skin Lightening Creams}

The trade names of the skin lightening creams used by the pregnant women are Movate, Carotone, Pure skin, Skin Light, Perfect White, Caro White, Looking Good and Clear Essence. The creams were classified those containing hydroquinone (Caro White, Carotone, Skin Light and Looking Good) and those not containing hydroquinone (Movate, Perfect White, Pure Skin and Clear Essence) based on manufacturers instruction. The creams were diluted 1:64 with de-ionized water before $\mathrm{Hg}$ analysis.

\section{Sample Collection}

Institutional ethical approval was obtained from University of Ibadan/University College Hospital Ibadan Ethical Review Committee. Informed consent was obtained from mothers before sample collection. Five milliliters $(5 \mathrm{ml})$ of venous blood and colostrumwere collected from each mother. Also $5 \mathrm{ml}$ of cord blood was collected from babies after cord clamping during delivery. The blood samples were collected into sterile plain tubes and spun at 3000rpm for 5 minutes to obtain serum and stored at $-20^{\circ} \mathrm{C}$ until analysis. Breast milk samples were collected by manual expression into sterile plain tubes, spun at 3000rpm for 5 minutes. The fat layer was carefully removed to obtain fatfree milk plasma and then stored at $-20^{\circ} \mathrm{C}$ until analysis. The samples were collected with the assistance of a Gynecologist.

\section{Determination of Mercury levels by (AAS) Technique}

Atomic absorption Spectrophotometry (AAS) is a spectro analytical procedure for the quantitative determination of chemical elements using the absorption of optical radiation (light) by free atoms in the gaseous state. The technique makes use of absorption spectrometry to assess the concentration of 
an analyte in a sample. It requires standards with known analyte content to establish the relation between the measured absorbance and the analyte concentration and relies on the Beer-Lambert Law. The electrons of the atoms in the atomizer can be promoted to higher orbitals (excited state) for a short period of time (nanoseconds) by absorbing a defined quantity of energy (radiation of a given wavelength). This amount of energy, that is, wavelength, is specific to a particular electron transition in a particular element. Generally, each wavelength corresponds to only one element, and the width of an absorption line is only of the order of a few picometers (pm), which gives the technique its elemental selectivity. The radiation flux without a sample and with a sample in the atomizer is measured using a detector, and the ratio between the two values (the absorbance) is converted to analyte concentration or mass using the Beer-Lambert Law.

\section{Measurement of Immunoglobulin Classes (IgG, $\lg \mathrm{A}$ and $\lg \mathrm{M})$ by ELISA Technique}

Levels of immunoglobulin classes (IgG, IgA and IgM) were determined by enzyme-linked immunosorbent assay (ELISA) as previously described [9]. A fixed volume per well of appropriate sample dilution buffer, antigen standard cocktail, or an experimental sample was pipetted into microtiter plates. This sample was incubated at room temperature $\left(25-27^{\circ} \mathrm{C}\right)$ for a specified length of time based on the micronutrient being analyzed. The ELISA immunoplate was washed 3 times with $350 \mu \mathrm{l} /$ well of washing buffer. Then $100 \mu \mathrm{l}$ per well of detection antibodies was added. This mixture was incubated at room temperature for 60 minutes. The immunoplate was rewashed 3 times with $350 \mu \mathrm{l} /$ well of washing buffer. A concentration of $100 \mu \mathrm{l} /$ well of diluted Avidin-HRP conjugate was added, after which the plate was incubated at room temperature for 30 minutes in darkness. The plate was washed 4 times and $100 \mu \mathrm{l} /$ well of developing solution was added. The reaction was stopped with $100 \mu \mathrm{l} /$ well of Stop Solution and the optical density (OD) was read at specified wavelength within 30 minutes following the addition of Stop Solution. The average absorbance value of each OD was plotted against corresponding cytokine values to create a standard curve. The average absorbance of each serum sample was used to determine corresponding immunoglobulin values by interpolating from the curve. The samples were run in duplicates and with the technician being unaware of which fuel group the samples came from.

\section{Statistical Analysis}

The results obtained were expressed as mean \pm standard deviation ( $\overline{\mathrm{x}} \pm$ S.D) and compared using student t-test, Pearson analysis was used to correlate the levels of immunoglobulin classes with levels of $\mathrm{Hg}$. The differences were statistically regarded as significant at $\mathrm{p}<0.05$.

\section{RESULTS}

A total of sixty (60) pregnant Nigeria women participated in this study. Thirty (30) of them were daily users of skin lightening creams for between 6-7 years, while the remaining thirty subjects were pregnant nonusers of skin lightening creams served as controls. The subjects were recruited from two maternity centers in Ibadan, Nigeria. Those on special medication, history of recent blood transfusion, those with various infections, those with complicated pregnancy, those on special diet and those with pre-term delivery were excluded from the study. The mean age of users of skin lightening cream was $27.8 \pm 3.7$ years while that of the control was $28.0 \pm 5.6$ years.

Table 1 presents the levels ( $\overline{\mathrm{x}} \pm \mathrm{SD}$ ) of $\operatorname{IgA}$, IgG and IgM in the maternal sera, cord blood sera and breast milk plasma of pregnant women using skin lightening creams compared with controls. The mean levels of maternal $\operatorname{IgA}$, cord IgA and breast milk IgA of the of the pregnant women using skin lightening creams were $240.02 \pm$ $86.63 \mathrm{mg} / \mathrm{dl}, 252.56 \pm 105.16 \mathrm{mg} / \mathrm{dl}$ and $236.55 \pm$ $97.81 \mathrm{mg} / \mathrm{dl}$ respectively, while the corresponding values in the control subjects were $236.87 \pm 59.53 \mathrm{mg} / \mathrm{dl}, 238.57$ $\pm 73.06 \mathrm{mg} / \mathrm{dl}$ and $234.74 \pm 79.57 \mathrm{mg} / \mathrm{dl}$ respectively. The levels of maternal IgG, cord IgG and breast milk $\mathrm{IgG}$ of the of the pregnant women using skin lightening creams were $1102.87 \pm 243.46 \mathrm{mg} / \mathrm{dl}, 1123.49 \pm$ $208.35 \mathrm{mg} / \mathrm{dl}$ and $1056.36 \pm 203.42 \mathrm{mg} / \mathrm{dl}$ respectively, while the corresponding values in the control subjects were $697.14 \pm 175.50 \mathrm{mg} / \mathrm{dl}, 702.15 \pm 215.03 \mathrm{mg} / \mathrm{dl}$ and $690.87 \pm 234.18 \mathrm{mg} / \mathrm{dl}$ respectively. The levels of maternal IgM, cord IgM and breast milk IgM of the pregnant women using skin lightening creams were $221.36 \pm 34.59 \mathrm{mg} / \mathrm{dl}, 229.78 \pm 50.33 \mathrm{mg} / \mathrm{dl}$ and 215.56 $\pm 46.73 \mathrm{mg} / \mathrm{dl}$ respectively while the corresponding values in the controls were $185.10 \pm 46.59 \mathrm{mg} / \mathrm{dl}, 186.43$ $\pm 57.09 \mathrm{mg} / \mathrm{dl}$ and $183.44 \pm 62.18 \mathrm{mg} / \mathrm{dl}$ respectively. There were no statistical significant difference between the levels of maternal IgA, cord IgA and breast milk $\operatorname{IgA}$ in the test participants when compared with the 
controls. Maternal serum IgG, cord IgG and breast milk IgG of the pregnant women using skin lightening creams were significantly higher when compared with the controls. Also, the mean maternal IgM, cord IgM and breast milk $\operatorname{IgM}$ of the pregnant women using skin lightening creams were significantly higher when compared with the controls ( $\mathrm{p}<0.05$ in each case). Table 2 presents the levels ( $\bar{x} \pm \mathrm{SD}$ ) of Ig classes (IgA, $\mathrm{IgG}$ and $\mathrm{IgM}$ ) in maternal sera, cord sera and breast milk plasma in users of hydroquinone containing skin lightening creams compared with the levels in users of non - hydroquinone containing creams.

No statistical significant differences were observed when the mean levels of maternal IgA (246.08 \pm $90.30 \mathrm{mg} / \mathrm{dl})$, cord $\operatorname{IgA}(256.21 \pm 111.91 \mathrm{mg} / \mathrm{dl})$ and breast milk IgA $(244.07 \pm 104.08 \mathrm{mg} / \mathrm{dl})$ in users of hydroquinone containing skin lightening creams were compared with the levels of maternal IgA (253.39 $\pm 78.02 \mathrm{mg} / \mathrm{dl})$, cord $\operatorname{IgA}(264.74 \pm 86.16 \mathrm{mg} / \mathrm{dl})$, and breast milk IgA $(260.54 \pm 78.98 \mathrm{mg} / \mathrm{dl})$ in users of non - hydroquinone containing skin lightening creams ( $p>0.05$ in each case). No statistical significant differences were observed when the mean levels of maternal IgG $(1093.68 \pm 219.21 \mathrm{mg} / \mathrm{dl})$, cord $\mathrm{IgG}$ $(1093.64 \pm 171.80 \mathrm{mg} / \mathrm{dl})$ and breast milk IgG (1047.30 $\pm 156.13 \mathrm{mg} / \mathrm{dl})$ in users of hydroquinone containing skin lightening creams when compared with the levels

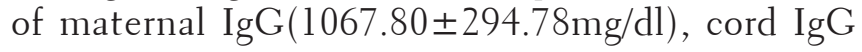

$(1092.79 \pm 247.25 \mathrm{mg} / \mathrm{dl})$ and breast milk $\operatorname{IgG}(1045.33$ $\pm 288.43 \mathrm{mg} / \mathrm{dl})$ in users of non-hydroquinone containing skin lightening creams $(p>0.05$ in each case). Also no statistical significant differences were observed when the mean levels of maternal IgM (223.80 $\pm 35.05 \mathrm{mg} / \mathrm{dl})$, cord $\operatorname{IgM}(229.17 \pm 55.49 \mathrm{mg} / \mathrm{dl})$ and breast milk IgM $(218.78 \pm 49.65 \mathrm{mg} / \mathrm{dl})$ in users of hydroquinone containing skin lightening creams were compared with the levels of maternal IgM (225.47 \pm $30.04 \mathrm{mg} / \mathrm{dl})$, cord $\operatorname{IgM}(233.62 \pm 32.33 \mathrm{mg} / \mathrm{dl})$ and breast milk $\operatorname{IgM}(221.41 \pm 35.11 \mathrm{mg} / \mathrm{dl})$, in users of non-hydroquinone containing skin lightening creams ( $p>0.05$ in each case).

Table 3 shows the levels ( $\overline{\mathrm{x}} \pm \mathrm{SD})$ of $\mathrm{Hg}$ in the maternal sera, cord sera and breast milk plasma of pregnant women using skin lightening creams compared with the control. No statistical significant differences were observed when $\mathrm{Hg}$ levels in the maternal sera $(0.35 \pm$ $0.06 \mu \mathrm{g} / \mathrm{dl})$, cord blood sera $(0.36 \pm 0.07 \mu \mathrm{g} / \mathrm{dl})$ and breast milk plasma of users of skin lightening creams when compared with levels of $\mathrm{Hg}$ in the maternal sera $(0.36 \pm 0.09 \mu \mathrm{g} / \mathrm{dl})$, cord blood sera $(0.35 \pm 0.08 \mu \mathrm{g} / \mathrm{dl})$ and breast milk plasma $(0.38 \pm 0.07 \mu \mathrm{g} / \mathrm{dl})$ of non users of skin lightening creams.

Table 4 presents the Mean Hg levels in maternal sera, cord blood sera and breast milk plasma of users of hydroquinone containing skin lightening

Table 1: The levels $(\bar{x} \pm S D)$ of IgA, IgG and IgM in the maternal sera, cord blood sera and breast milk plasma of pregnant women using skin lightening creams compared with controls

\begin{tabular}{|c|c|c|c|c|}
\hline Parameters & Pregnant women using skin lightening creams $(n=30)$ & Controls $(n=30)$ & t- values & P-values \\
\hline Maternal lgA (mg/dl) & $240.02 \pm 86.63$ & $236.87 \pm 59.63$ & 0.150 & 0.882 \\
\hline Cord IgA (mg/dl) & $252.56 \pm 105.16$ & $238.57 \pm 37.06$ & 0.546 & 0.587 \\
\hline Breast Milk IgA (mg/dl) & $236.55 \pm 97.81$ & $234.74 \pm 79.57$ & 0.072 & 0.943 \\
\hline Maternal lgG (mg/dl) & $1102.87 \pm 43.46$ & $697.14 \pm 175.50$ & 6.76 & $0.000^{*}$ \\
\hline Cord lgG (mg/dl) & $1123.49 \pm 208.35$ & $702.15 \pm 215.03$ & 7.04 & $0.000^{*}$ \\
\hline Breast Milk lgG (mg/dl) & $1056.36 \pm 03.42$ & $690.87 \pm 234.18$ & 5.89 & $0.000^{*}$ \\
\hline Maternal lgM (mg/dl) & $221.36 \pm 34.59$ & $185.10 \pm 46.59$ & $\begin{array}{l}3.12 \\
285\end{array}$ & $0.003^{*}$ \\
\hline Cord IgM (mg/dl) & $229.78 \pm 50.33$ & $186.43 \pm 57.09$ & 2.85 & $0.006^{*}$ \\
\hline Breast Milk lgM (mg/dl) & $215.56 \pm 46.73$ & $183.44 \pm 62.18$ & 2.07 & $0.044^{*}$ \\
\hline
\end{tabular}

*Statistically significant.

Table 2: The levels ( $\bar{x} \pm S D)$ of Ig classes ( $\lg A$, IgG and $\lg M)$ in maternal sera, cord sera and breast milk plasma of users of hydroquinone containing skin lightening creams compared with the levels in users of non - hydroquinone containing creams

\begin{tabular}{|c|c|c|c|c|}
\hline Parameters & $\begin{array}{l}\text { Users of hydroquinone } \\
\text { containing creams }(n=14)\end{array}$ & $\begin{array}{l}\text { Users of non-hydroquinone } \\
\text { containing creams }(n=16)\end{array}$ & t-values & p-values \\
\hline Maternal IgA (mg/dl) & $246.08 \pm 90.30$ & $253.39 \pm 78.02$ & 0.194 & 0.848 \\
\hline Cord $\lg A(\mathrm{mg} / \mathrm{dl})$ & $256.21 \pm 111.91$ & $264.74 \pm 86.16$ & 0.190 & 0.851 \\
\hline Breast Milk IgA (mg/dl) & $244.07 \pm 104.08$ & $260.54 \pm 78.98$ & 0.379 & 0.709 \\
\hline Maternal lgG (mg/dl) & $1093.68 \pm 219.21$ & $1067.80 \pm 294.78$ & -0.231 & 0.820 \\
\hline Cord IgG (mg/dl) & $1093.64 \pm 171.80$ & $1092.79 \pm 247.25$ & 0.190 & 0.851 \\
\hline Breast Milk lgG (mg/dl) & $1047.30 \pm 156.13$ & $1045.33 \pm 288.43$ & 0.379 & 0.709 \\
\hline Maternal lgM (mg/dl) & $223.80 \pm 35.05$ & $225.47 \pm 30.04$ & 0.115 & 0.910 \\
\hline Cord IgM (mg/dl) & $229.17 \pm 55.49$ & $233.62 \pm 32.33$ & 0.214 & 0.833 \\
\hline Breast Milk IgM (mg/dl) & $218.78 \pm 49.65$ & $221.41 \pm 35.11$ & 0.136 & 0.894 \\
\hline
\end{tabular}


www.odermatol.com

Table 3: The levels $(\underline{\bar{x}} \pm S D)$ of $\mathrm{Hg}$ in the maternal sera, cord sera and breast milk plasma of pregnant women using skin lightening creams compared with the controls

\begin{tabular}{|c|c|c|c|c|}
\hline Parameters & Test $(n=30)$ & Controls $(n=30)$ & t-values & p-values \\
\hline Maternal $\mathrm{Hg}(\mu \mathrm{g} / \mathrm{dl})$ & $0.35 \pm 0.06$ & $0.36 \pm 0.09$ & 0.982 & 0.331 \\
\hline Cord $\mathrm{Hg}(\mu \mathrm{g} / \mathrm{dl})$ & $0.36 \pm 0.07$ & $0.35 \pm 0.08$ & 0.439 & 0.663 \\
\hline Breast Milk Hg $(\mu \mathrm{g} / \mathrm{dl})$ & $0.35 \pm 0.08$ & $0.38 \pm 0.07$ & 1.721 & 0.920 \\
\hline
\end{tabular}

Table 4: Mean Hg levels in maternal sera, cord blood sera and breast milk plasma of users of hydroquinone containing skin lightening creams compared with the levels in users of non - hydroquinone containing creams.

\begin{tabular}{lccc}
\hline Parameters & $\begin{array}{c}\text { Users of hydroquinone containing } \\
\text { creams }(\mathbf{n}=\mathbf{1 4})\end{array}$ & $\begin{array}{c}\text { Users of non-hydroquinone containing } \\
\text { creams }(\mathbf{n}=\mathbf{1 6})\end{array}$ & t-values \\
\hline Maternal Hg $(\mu \mathrm{g} / \mathrm{dl})$ & $0.37 \pm 0.05$ & $0.32 \pm 0.05$ & 2.181 \\
Cord $\mathrm{Hg}(\mu \mathrm{g} / \mathrm{dl})$ & $0.38 \pm 0.06$ & $0.36 \pm 0.05$ & $0.042^{*}$ \\
Breast Milk Hg $(\mu \mathrm{g} / \mathrm{dl})$ & $0.35 \pm 0.06$ & $0.35 \pm 0.10$ & 0.400 \\
\hline
\end{tabular}

*Statistically significant.

creams compared with the levels in users of non-hydroquinone containing creams. There was no statistical significant difference between cord plasma $\mathrm{Hg}(0.38 \pm 0.06 \mu \mathrm{g} / \mathrm{dl})$ and breast milk $\mathrm{Hg}(0.35 \pm$ $0.06 \mu \mathrm{g} / \mathrm{dl})$ of users of hydroquinone containing skin lightening creams when compared with levels in cord blood sera $(0.36 \pm 0.05 \mu \mathrm{g} / \mathrm{dl})$ and breast milk plasma $(0.35 \pm 0.10 \mu \mathrm{g} / \mathrm{dl})$ of users of non-hydroquinone containing skin lightening creams but statistical significant difference existed between the levels of $\mathrm{Hg}$ in maternal sera $(0.37 \pm 0.05 \mu \mathrm{g} / \mathrm{dl})$ of users of hydroquinone containing skin lightening creams when compared with the levels of $\mathrm{Hg}(0.32 \pm 0.05 \mu \mathrm{g} / \mathrm{dl})$ in users of non-hydroquinone containing creams.

Table 5 presents the correlation between levels of IgA, IgG and IgM with Hg levels in the maternal sera, cord sera and breast milk plasma of the pregnant women using skin lightening creams. While there were positive correlations between maternal $\mathrm{IgA}$ with maternal $\mathrm{Hg}$ $(\mathrm{r}=0.584)$, maternal IgM with maternal $\mathrm{Hg}(\mathrm{r}=0.567)$ and negative correlation between cord IgG with cord $\mathrm{Hg}(\mathrm{r}=-0.518)$, no correlation existed between cord $\operatorname{IgA}$ with cord $\mathrm{Hg}(\mathrm{r}=0.051)$, breast milk IgA with breast milk Hg $(\mathrm{r}=0.040)$, maternal $\mathrm{IgG}$ with maternal $\mathrm{Hg}(\mathrm{r}=-0.348)$, breast milk $\mathrm{IgG}$ with breast milk $\mathrm{Hg}$ $(\mathrm{r}=-0.332)$, cord $\mathrm{IgM}$ with cord $\mathrm{Hg}(\mathrm{r}=-0.126)$ and breast milk IgM with breast milk Hg $(r=-0.211)$.

\section{DISCUSSION}

Mercury and hydroquinone are the two most common active ingredients in most skin lightening creams. Numerous potentially life-threatening consequences of these agents have been identified to include skin lesions, epidermal atrophy (thinning of the skin), exogenous ochronosis, eczema, bacterial and
Table 5: Correlation of levels of $\lg A$, IgG, IgM with $\mathrm{Hg}$ levels in the maternal sera, cord sera and breast milk plasma of pregnant women using skin lightening creams

\begin{tabular}{lcc}
\hline Correlation parameter & \multicolumn{2}{c}{ Subjects $(\mathbf{n = 3 0 )}$} \\
\cline { 2 - 3 } & $\mathbf{r}$ & $\mathbf{p}$ \\
\hline Maternal IgA Vs Maternal Hg & 0.584 & $0.002^{*}$ \\
Maternal IgG Vs Maternal Hg & -0.348 & 0.088 \\
Maternal IgM Vs Maternal Hg & 0.567 & $0.003^{*}$ \\
Cord IgA Vs Cord Hg & 0.051 & 0.807 \\
Cord IgG Vs Cord Hg & -0.518 & $0.008^{*}$ \\
Cord IgM Vs Cord Hg & -0.126 & 0.549 \\
Breast Milk IgA Vs Breast Milk Hg & 0.040 & 0.851 \\
Breast Milk IgG Vs Breast Milk Hg & -0.332 & 0.059 \\
Breast Milk IgM Vs Breast Milk Hg & -0.211 & 0.311 \\
\hline
\end{tabular}

*Statistically significant.

fungal infections, dermatitis, scabies, warts, acne, sun damage and body odour [10]. Long term use of products containing those agents can lead to fragile skin, poor wound healing, scarring and the need for corrective surgery [2]. Other more serious health risks include hypertension, diabetes, infertility, leukaemia (blood cancer), skin cancer, foetal toxicity (foetal poisoning), immunosuppression (suppression of a healthy immune response), renal and liver impairment and failure, Cushing's syndrome (hormone disorder), insomnia, memory loss, tremors, speech and hearing impairment [11]. Loss of innate functions of skin bleaching cream users was reported by [5], however, there was no report on the levels of Ig classes or $\mathrm{Hg}$ levels on maternal sera, cord sera $\mathrm{Hg}$ and breast milk plasma of users of hydroquinone containing skin lightening creams compared with users of nonhydroquinone containing creams.

Worthy of note is the fact that all the creams used by the subjects have $\mathrm{Hg}$ levels above a cosmetic reference value of $0.01 \mu \mathrm{g} / \mathrm{dl}$ recommended by W.H.O [12]. There was no statistically significant difference between the cord sera $\mathrm{Hg}$ and breast milk plasma $\mathrm{Hg}$ of users of 
hydroquinone containing skin lightening creams when compared with users of non- hydroquinone containing creams. This might be related to equal exposure to environmental $\mathrm{Hg}$ from sources such as mercury vapor from broken thermometer, medical equipment, valves, improperly disposed batteries or eating fishes from $\mathrm{Hg}$ contaminated water $[12,13,18]$.

However, significant increase observed in maternal $\mathrm{Hg}$ of users of hydroquinone containing skin lightening creams when compared with users of non- hydroquinone containing creams, could be that environmental $\mathrm{Hg}$ absorption through the skin is aggravated by hydroquinone in the skin lightening cream users.

Statistical significant differences were observed between maternal serum IgG, cord IgG, breast milk IgG, maternal IgM, cord IgM and breast milk IgM of the pregnant women using skin lightening creams when compared with the control. Higher levels of $\operatorname{IgG}$ in pregnant women using skin lightening creams could be as a result of chronic stimulation of immune system by long term use of skin lightening creams by the subjects because IgM is predominantly produced during acute immune responses as shown in table 1 while $\operatorname{IgG}$ is predominantly produced during chronic immune response [14]. No statistically significant differences were observed between the levels of maternal IgA, cord IgA, and breast milk IgA of the users of hydroquinone containing skin lightening creams when compared with users of non- hydroquinone containing skin lightening creams. This could be due to the fact that IgA is commonly increased in cases of liver cirrhosis, autoimmune disorder such as rheumatoid arthritis and immunologic deficiency state, and infections of respiratory, reproductive and digestive tracts [15]. There was no statistical significant difference observed between the levels of maternal $\mathrm{IgG}$, cord $\mathrm{IgG}$, and breast milk $\mathrm{IgG}$ of the users of hydroquinone containing skin lightening creams when compared with users of non-hydroquinone containing skin lightening creams. There was no report available on the link between hydroquinone containing skin lightening creams and the levels of IgG. No statistical significant difference was observed between the levels of maternal IgM, cord IgM, and breast milk IgM of the users of hydroquinone containing skin lightening creams when compared with users of non- hydroquinone containing creams. It is possible that hydroquinone has no degradative effect on the levels of IgM, accounting for IgM stability in both groups. No statistical significant differences were observed between the levels of maternal mercury, cord mercury, and breast milk mercury of the users of skin lightening creams when compared with the controls.

Despite the fact that Hg levels in the skin lightening creams used by the test participants contained $\mathrm{Hg}$ levels above cosmetic reference value of $0.01 \mu \mathrm{g} / \mathrm{dl}$ as recommended by WHO [11]. It might be hypothesized that there are intricate mechanisms in users of these creams that reduces their blood Hg levels. This may include $\mathrm{N}$-acetyl cysteine which is the derivative of naturally occurring amino acid (Cysteine). Cysteine is an excellent source of sulfhydryl (-SH) groups which stimulates synthesis of reduced glutathione (GSH). GSH binds mercury for easy excretion. Eggs and garlic are sulfur-containing nutrients and also rich in sulfhydryl (-SH) group which complex with mercury. Also, eggs and whole grains are rich in Se which protects against mercury toxicity and alters the distribution of mercury in tissues by binding of $\mathrm{Hg}$ Se complexes to proteins, hence promoting mercury excretion $[16,19,20]$.

While positive correlation was observed between maternal IgA with maternal mercury, maternal IgM with maternal mercury and negative correlation was observed between cord $\mathrm{IgG}$ with cord $\mathrm{Hg}$. The positive correlation between maternal IgA and maternal mercury of the pregnant women using skin lightening creams could be as a result of localized or systemic infection resulting from chronic exposure to mercury contained in the skin lightening creams used by the subjects as it has been reported that constant exposure to mercury particularly through the use of skin lightening creams, can lead to increased susceptibility of users to localized or systemic infections $[5,17]$. Negative correlation between cord IgG with cord $\mathrm{Hg}$ indicated that the higher the mercury level, the lower the cord $\mathrm{IgG}$ level in the fetus. The implication is that IgG levels will be reduced in the fetus if skin lightening practice is not discontinued by the users as it has been found that pregnant mothers using skin lightening creams had smaller placenta and their children born at low birth weights, low cortisol levels, and higher rates of birth defects as a result of mercury exposure [7]. Also, reduced innate immunity of the skin as a result of removal of top (epidermal layer) of the skin, reduced melanin and direct effect of sun rays might cause higher susceptibility to infections in skin lightening cream users.

In conclusion, raised $\operatorname{IgG}$ and $\operatorname{IgM}$ in mothers and babies of chronic skin lightening creams users could 
be a result of polyclonal B lymphocyte activation which could lead to autoimmune disease later in life. Also, $\mathrm{Hg}$ but not hydroquinone had negative effect on babies' immunoglobulin levels. There is need for public awareness programs to enlighten the populace about the danger involved in the use of skin lightening creams particularly among pregnant women. Numerous potentially life-threatening consequences especially autoimmune disorder awaits any long term user of skin lightening cream particularly pregnant mothers.

There is need for public awareness programs to enlighten the populace about the danger involved in the long term use of skin lightening creams particularly to pregnant women.

\section{Statement of Human and Animal Rights}

All procedures followed were in accordance with the ethical standards of the responsible committee on human experimentation (institutional and national) and with the Helsinki Declaration of 1975, as revised in 2008.

\section{Statement of Informed Consent}

Informed consent was obtained from all patients for being included in the study.

\section{REFERENCES}

1. Olumide YM. Use of skin lightening creams. Brit Med J. 2010;341:6102.

2. Benn EK, Alexis A, Mohamed N, Wang YH, Khan IA, Liu B. Skin bleaching and Dermatologic Health of African and Afro-Caribbean populations in the US: New directions for methodologically rigorous, multidisciplinary, and culturally sensitive research. Dermatol Ther (Heidelb). 2016;6:453-459.

3. Ladizinski B, Mistry N, Kundu R. Wide spread use of toxic skin lightening compounds: medical and psychosocial aspects. Dermatol Clin J. 2011;29:111-23.

4. Traore A, Kadeba JC, Niamba P, Barro F, Ouedraogo L. Use of cutaneous de-pigmenting products by women in two towns in Burkina Faso: epideminologic data, motivations, products and side effects. Int J Dermatol. 2005;44 suppl 1:30-2.

5. Arinola OG, Afolabi KA. and Olopade CO. Immunological skin tests and hematological indices in Nigeria users of skin lightening creams. Egyptian Dermatol Online J. 2012;7:3.

6. Mohammed T, Mohammed E, Bascombe S. The evaluation of total mercury and arsenic in skin bleaching creams commonly used in Trinidad and Tobago and their potential risk to the people of the
Caribbean. J Public Health Res. 2017;6:1097.

7. Bahari M, Alizadeh Oskoee P, Savadi Oskoee S, Pouralibaba F, Morsali Ahari A. Mercury release of amalgams with various silver contents after exposure to bleaching agent. J Dent Res Dent Clin Dent Prospects. 2016;10:118-23.

8. Sendrasoa FA, Ranaivo IM, Andrianarison M, Raharolahy O, Razanakoto NH, Ramarozatovo LS, et al. Misuse of topical corticosteroids for cosmetic purpose in Antananarivo, Madagascar. Biomed Res Int. 2017;2017:9637083.

9. Olayanju OA, Rahamon SK, Arinola OG. Salivary immunoglobulin classes in Nigerian cigarette smokers: Indication for increased risk of oral diseases. Dent Res J. 2012;9:531-4.

10. Alobaidi AH, Hamad ES, Kudair KA, Alsamarai AM. Formulation of hypopigmentation cream and evaluation of its effect on skin pigment. Part I: Formulation of the product. Our Dermatol Online. 2014;5:9-13.

11. Taylor SC. Skin of color: biology, structure, function, and implications for dermatologic disease. J Amer Acad Dermatol. 2002;46:S41-S62.

12. WHO. 2003. Elemental Mercury and Inorganic Mercury Compounds. World Health Organization and International Programmer on Chemical Safety, Geneva.

13. Michalek IM, Benn EKT, Dos Santos FLC, Gordon S, Wen C, Liu B. A systematic review of global legal regulations on the permissible level of heavy metals in cosmetics with particular emphasis on skin lightening products. Environ Res. 2018;170:187-93.

14. Azarsiz E, Karaca NE, Gunaydin NC, Gulez N, Ozturk C, Aksu G, et al. Do elevated serum IgM levels have to be included in probable diagnosis criteria of patients with ataxia-telangiectasia? Int J Immunopathol Pharmacol. 2014;27:421-7.

15. Fagarasan S, Honjo T. Intestinal IgA synthesis: regulation of frontline body defences. Nature Reviews. Immunology. 2003;3:63-72.

16. Khalaf AA, Ahmed W, Moselhy WA, Abdel-Halim BR, Ibrahim MA. Protective effects of selenium and nano-selenium on bisphenol-induced reproductive toxicity in male rats. Hum Exp Toxicol. 2018:960327118816134.

17. Dioussé P, Ndiaye M, Dione H, Bammo M, Sow O, Seck F, et al. Bacterial dermohypodermitis at the Thies Regional Hospital, Senegal (West Africa): A retrospective study of 425 cases. Our Dermatol Online. 2017;8:233-6.

18. Kisiel K, Dębowska R, Dzilińska K, Radzikowska A, PasikowskaPiwko M, Rogiewicz K, et al. New $\mathrm{H}_{2} \mathrm{O}_{2}$ dermocosmetic in acne skin care. Our Dermatol Online. Our Dermatol Online. 2018;9(e):e3.

19. Huang H, Wang Y, An Y, Tian Y, Li S, Teng X. Selenium for the mitigation of toxicity induced by lead in chicken testes through regulating mRNA expressions of HSPs and selenoproteins. Environ Sci Pollut Res Int. 2017;24:14312-21.

20. Abreu Velez AM, Yepes Naranjo MM, Avila IC, Londoño ML, Googe Jr. PB, Velásquez Velez JE, et al. Tissue inhibitor of metalloproteinase 1, matrix metalloproteinase 9, ,lpha-1 antitrypsin, metallothionein and urokinase type plasminogen activator receptor in skin biopsies from patients affected by autoimmune blistering diseases. Our Dermatol Online. 2013;4:275-80.

Copyright by Agatha Obiageli Nwosu, et al. This is an open-access article distributed under the terms of the Creative Commons Attribution License, which permits unrestricted use, distribution, and reproduction in any medium, provided the original author and source are credited.

Source of Support: Nil, Conflict of Interest: None declared. 